\title{
A Relationship between Natural Disaster and Poverty
}

\author{
P. R. Awasthi \\ National Field Coordinator \\ United Nations Resident Coordinator's Office, Nepal \\ Email: prem.awasthi@gmail.com
}

\begin{abstract}
This paper aims to discuss the impact of a disaster on the lives and livelihood and how it contributes to poverty. For this purpose, two major disasters in recent history were taken as reference. The common approach in defining and measuring poverty is the monetary approach; often disaster has seen only a matter of humanitarian importance. Nepal as a prone to different kinds of natural disasters has a significant impact on lives and livelihood as well. Despite this fact, poverty is narrowly defined. As there is a significant linkage between disaster risk and poverty, the poverty-related discussions must incorporate the impact and risk of disaster while formulating poverty reduction related policies.
\end{abstract}

Key Words: Disaster, poverty, vulnerability, economic loss, livelihood

\section{Introduction}

The natural disasters have a considerable impact on the lives and livelihood of people. Nepal being the Himalayan country is vulnerable to different natural and human-induced disasters. Given its geographic location and geophysical characteristics, it regularly experiences a natural disaster. Notably, more than 80 percent of the population is at risk from different hazards such as flood, landslide, earthquake, fire, and hailstorm. A natural hazard is a condition that may cause loss of life, injury, property damage; loss of livelihoods social and economic disruptions; and environmental damage (UNISDR, 2009). All-natural phenomena may not be a hazardous or disastrous. A disaster is defined as a serious disruption of the functioning of a community or a society, involving widespread human, mental, economic and/ or environmental losses and impacts that exceed the ability of the affected community to cope using its own resources (UNISDR, 2009).

Nepal is among the 20 most disaster-prone countries in the world. Globally Nepal ranks $4^{\text {th }}$ and $11^{\text {th }}$ for its vulnerability to climate change and earthquakes respectively (MoHA, 2015). The Ministry of Home Affairs (MoHA) has recorded a total of 16 kinds of disaster in country such as heavy rainfall, hailstorms, avalanche, cold wave, earthquake, flood, landslide etc. For the period of 2015 to 2016 a total of 2,940 disasters in which 9,698 people were killed, 1,085,797 houses damaged, NPR 709,788,288,091 of economic loss and 1,086,420 families were affected (MoHA, 2017). The figures are remarkably high mainly due to the earthquake in 2015, but annually hundreds of people are killed, thousands are displaced, and millions of economic losses occur due to recurring nature of disaster.

In 2017 flood and landslide during the monsoon season killed 134 people, and destroyed 43,400 houses, 191,700 houses were partially damaged, and 20,900 families were temporarily displaced, and around $1,688,474$ people were affected (NPC, 2017). Further to the loss of life, injuries the natural disaster also significantly damages property, destruction of assets, loss of services, social and economic disruption and environmental degradation.

This demonstrates that the natural disaster has a considerable impact on the lives and livelihoods of people of Nepal, and widely recognized for affecting disproportionately the poorest in a community due to their higher exposure and vulnerability to disasters. Additionally, recurrent events exacerbate the vulnerability of the poor to the disasters further increasing poverty level and often unable to break the poverty cycle.

\section{Disaster Risk and Poverty}

Different methods and concepts are used in defining poverty- the concept may directly have a policy implication in addressing the problems. However, the definition of poverty is contextual and relative with given set of standards and priorities. Poverty is usually considered an important factor for determining household vulnerability to hazards because household income level determines people's coping and adaptation capacities. Moreover, poverty exacerbates the negative effects of disaster on households, increasing the severity of existing poverty. 


\section{8 | Journal of APF Command and Staff College}

The most common definition is based on household and per person incomes. A person is considered to be poor if his or her income level falls below some minimum level necessary to meet needs such as housing, food, clothing, education, health and so on. This minimum level is called the 'poverty line'. The World Bank defines the global poverty line to be in the range of US\$ 1.25 and US\$ 2 per day. An alternative measure used to describe poverty is the ability to meet basic needs. The basic needs poverty is the minimum income that an individual requires to meet his or her basic needs and is based on the food poverty line and the non-food poverty line.

There is a considerable anecdotal evidence of a link between disaster risk and poverty. It is often seen that the poor families often live on marginal lands and in poorly constructed houses, with poor access to basic services. Majority of poor live in poorly constructed houses and have poor access to basic needs, and often do not have food and minimum level of nutrition. Living in poverty thus increases their vulnerability to disaster. Furthermore, given limited income and savings, the ability of the poor to respond to and recover from disaster is limited. Furthermore, the poor cannot easily adapt to disaster by investing on disaster-proof technology, relocating to less hazardous areas, replacing lost items and even taking out insurance (World Bank, 1997).

It has been noted that disaster can even induce or source of the poverty, especially among those living near the poverty line. Often it is seen that the destruction of assets of the poor during disaster trap families in chronic poverty because they lack necessary resources to rebuild their homes, replace assets and meet back needs. The ability of community to cope with and recover from disaster also depends on access to natural resources, human capital, physical asset and financial resources available to people (Carney, 1998). It is also often stated that recurring disasters can hold back development and progress towards national development goals.

The impact of natural disasters at the community is, however, not merely a matter of social and humanitarian importance; they are of economic importance too. The impact of disaster at household, communities and national levels limits their ability to respond to and recover and rehabilitate from distastes.

\section{Earthquake 2015}

The earthquakes have disproportionately affected the poorer, in both rural and urban areas (NPC 2015). Even within a prosperous area such as Kathmandu Valley, households that were already poor were severely affected. According to the World Bank the earthquakes pushed around 700,000 additional people (2.5 to 3.5 percent of total population) in poverty. As the communities were vulnerable prior to earthquake there were roughly 50 to 70 of increase in poverty in the rural areas of mountains and hills in the earthquake affected districts. Additionally, the deterioration of water and sanitation services, disruption of schools and health services, and the food insecurity led to a bigger impact on multidimensional poverty. The loss of poorly built residential houses; farmland and livestock amplified livelihood difficulties, and pushed poor households below the poverty line for extended period. The earthquakes have affected the livelihoods of about 2.287 million households and 5.6 million workers across 31 affected districts.

Although human development (HD) is to a large extent intangible, there are several indicators that can capture relevant dimensions of it, such as income, assets, health, education, inequity, gender inequality, child welfare, and security. All of these have been affected by the earthquake, the duration of the negative impact lasted for long as recovery efforts were prolonged. Poverty is one of the most important considerations, because it affects all other aspects of HD. There is a significant proportion of the Nepali population that subsists just above the US\$1.25 line but below \$2. The vulnerability of this group, especially female-headed families and those with a high-dependency rate is a serious concern. The second immediate effect has been felt in education, especially in the schooling due to the destruction of schools and mental trauma experienced by students.

A damage and loss to productive assets have exacerbated poverty. On the one hand, damage or destruction of houses implies the loss of rental income for many households and, on the other, signifies higher rental costs for those households previously living in rented dwellings. Destruction of productive assets such as land, seeds, machineries and working tools led to limited economic activities in the aftermath of the earthquakes. Finally, the earthquake ended up pushing an additional $2.5-3.5 \%$ Nepalis below the poverty line in rural central hills and mountains. 


\section{Tarai Flooding 2017}

Nepal experienced incessant rainfall from August 11 to14, 2017, resulting in widespread floods across 35 of the country's 77 districts. Several districts experienced the heaviest rainfall in over 60 years. This led to the inundation of about 80 percent of the land in substantial parts of the Tarai region (NRCS, 2017). The total damage caused by the floods is NPR 60,716.6 (USD 584.7) million, which almost amounts to 3 percent of Nepal's GDP. The household sector accounts for the largest share of damages as many homes and standing crops were damaged. Income losses were not significant, the floods, however, have a larger impact on the local economy as a result of extensive damage to rural infrastructure in the Tarai region. As some of the affected districts are already among lowest on the Human Development Index (HDI), the difference in income and access to basic services will widen gap between people living in the flood affected areas and other parts of the Terai.

The percentage of population living below the poverty line is higher in the Terai region than in the hills. The economy in the Terai is much less diversified, and more than 70 percent of the people depend on subsistence farming. Further, households in the region are larger in size with smaller landholdings. A slow rate of growth in the agriculture sector has not helped people rise above the poverty level, fueling an epic scale of temporary out-migration over the past decade. At the household level, food insecurity and poor nutrition are major concerns. Damage to houses and destruction of standing crops will pose serious problems for these households.

\section{Conclusions}

The natural disasters are in an increasing trend over the last decades- the climate change and human interventions such as infrastructure development and deforestation have further exacerbated people's exposure to the hazards. Every year more people are exposed to different kinds of hazards. Furthermore, there is a huge loss in economy and livelihood of people, often the disaster disproportionately affects the poor and marginalized people as they are highly exposed to hazards and underlying vulnerabilities. Given the lack of resources to recover, more often the disaster further poor people below the poverty line. Therefore, there is high need to consider building resilience or strengthening coping mechanism of the community against any kinds of hazardous events.

\section{References}

Carney, D. (1998). Sustainable livelihoods: What contributions can we make?. Papers presented at the Department of International Development's Natural Resources Advisers Conference, London.

Disaster Risk Reduction. (2009). UNISDR terminology on disaster risk reduction. Bangkok.

Ministry of Home Affairs. (2018). Nepal disaster report, 2017: The road to Sendai. Kathmandu: Government of Nepal.

Nepal Red Cross Society. (2017). IRA compilation report. Retrieved September 2, 2018, from http://www.ain.org.np/uploads/Floodrelief/floodreport.pdf

NPC. (2015 a). Nepal Earthquake 2015: Post disaster needs assessment: Key findings, Vol.A. Kathamndu: National Planning Commission, Government of Nepal.

NPC. (2017b). Nepal Flood 2017: Post flood recovery needs assessment. Kathmandu: National Planning Commission (NPC), Government of Nepal.

Sawada, Y., \& Takasaki, Y. (2017). Natural disaster, poverty, and development: An introduction. World Development, Elsevier.vol.94, 2-15.

UNISDR (United Nations International Strategy for Disaster Reduction Secretariat) 2007a. Assessing the relationship between natural hazards and poverty: A conceptual and methodological proposal. Paper prepared for the UNISDR-UNDP Disaster Risk-Poverty Regional Workshops in Bangkok, Thailand (22-24 April 2008) and Bogota, Colombia (10-11 June 2008). Geneva. 